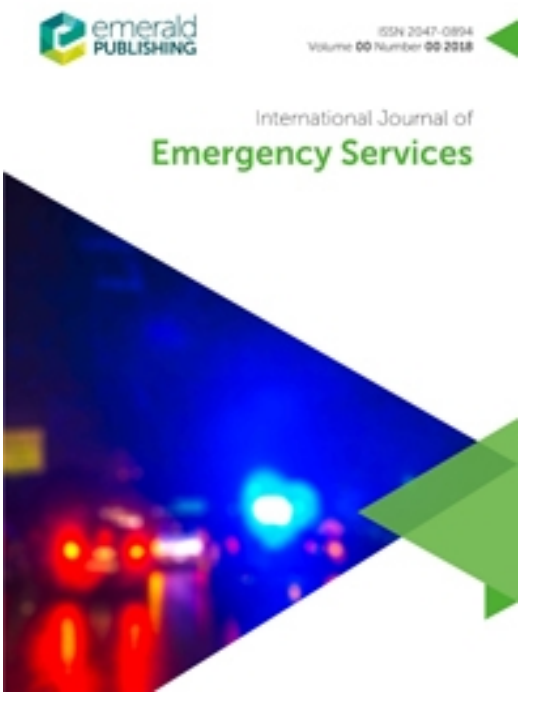

Service and value co-production and co-creation in emergency services and emergency management

\begin{tabular}{|r|l|}
\hline Journal: & International Journal of Emergency Services \\
\hline Manuscript ID & IJES-04-2020-0017 \\
\hline Manuscript Type: & Editorial \\
\hline \multicolumn{2}{l}{} \\
\hline
\end{tabular}

SCHOLARONE ${ }^{m}$

Manuscripts 


\title{
Service and value co-production and co-creation in emergency services and emergency management
}

\author{
Lucia Velotti, Assistant Professor, City University of New York (CUNY)
}

Peter Murphy, Professor of Public Policy and Management, Nottingham Trent University

\section{Introduction}

This special issue explores the phenomenon of co-producing and co-creating services, policies and knowledge and the creation or destruction of value in the delivery of emergency services and more broadly in the research and practice of emergency management.

Some of the papers in this issue were presented at the XXII International Research Society for Public Management (IRSPM) annual conference held in Edinburgh, Scotland in 2018 on the theme of "Creating and co-creating value in public service delivery". Other papers in the special issue result from a subsequent call for papers on the same theme of the conference.

The special issue seeks to understand what should be considered as value in the co-production and co-creation of emergency services and emergency management since it is not always clear what "value" is and for whom it is created. In addition, the special issue offers a reflection upon the current concepts of co-production, co-creation and public value creation and links this discourse to the field of emergency management. These issues are exemplified by the domestic and international response to Covid-19. At the time of writing many governments are asking citizens to self-isolate if they or emergency response teams suspect they may have the virus, or to 'socially distance' if citizens are in a 'vulnerable' group. They are in effect asking for voluntary behavioral changes from the public as part of policy development and implementation. Whether a more or less prescriptive approach is adopted by governments, all approaches have acknowledged that the response of users and members of the community is crucial to both the direction and the success of the policy adopted.

In this editorial we will first discuss what co-production and co-creation is in emergency management and emergency services, then we will present the articles of the special issue and how they relate to the topic of co-creation and co-production and finally we will provide some suggestions for further research and theoretical development.

\section{Co-production and co-creation in emergency services and emergency management}

The term co-production indicates "a process through which inputs from individuals who are not "in" the same organization are transformed into goods and services" (Ostrom 1996, p. 1073). The importance of the topic of co-production and co-creation lies in the fact that it recognizes the need to break the silos of disciplinary and/or professional knowledge to solve complex problems and deliver more satisfactory and effective services and policies. In essence, the government, at all levels, increasingly recognizes that it cannot deliver all services and policies on its own and sometimes needs the help of the whole community to be effective. This way of managing and administering public goods represents a conceptual shift in emergency management and in the public sector in general. For example, in the United States emergency preparedness is now seen as a shared responsibility across federal, state and local levels of government and within the 
community. Examples of this shift can be seen in the Federal Emergency Management Agency's promotion of the "Whole Community" approach (FEMA, 2011) and the recently released "Building cultures of Preparedness" (FEMA, 2018). Thus, service users and policy recipients now have to be taken into account during the design stage of a service since "the delivery and management of services are no longer just the preserve of professionals and managers - users and other members of the community are playing a large role in shaping decisions and outcomes" (Bovaird 2007, p.846). A requirement exemplified by the response to the outbreak of Covid-19 pandemic in both the United States, and the UK where, in March, the president declared a national emergency invoking both the National Emergencies Act and the 1988 Stafford Act and the Prime Minister announced that he would be proposing a plethora of new emergency powers (Johnson 2020).

This radical new approach to the field of emergency management potentially changes the definition and scope of emergency services. The conventional definition of emergency services as performed by trained professional in the sector of law enforcement, fire and rescue services and emergency medical services should now also include co-opted and spontaneous volunteers acting as first responders. Emergency services have often relied on co-opted but pre- trained volunteers in the past. An example of spontaneous volunteers acting as s responders in the United States is the Cajun Navy. The Cajun Navy is a group of people with boats that provide rescue services to people in the event of flooding. Like the Cajun Navy, other groups or spontaneous volunteers provide both emergency services and relief in the aftermath of a disaster. For instance, in Australia in the aftermath of the 2011 Queensland floods the "mud army" helped with the cleanup operations (Rafter, 2013). However, the response of Europe and the United States to the spread of Covid-19 represents attempts at mass mobilization and significant behavioral change in the preparedness stage as opposed to the reaction and recovery phases. It is distinctly possible that mass mobilization may also be required in the recovery stage of the Covid-19 outbreak to avoid a renewed resurgence of the virus.

The involvement of citizens or private entities in the production, creation and/or delivery of services and policies results in more or less formalized public-private partnerships and in processes of co-production and/or co-creation. Co-production and co-creation are two ways of working in public-private partnerships (Velotti, Botti and Vesci, 2012; Dudau, Glennon and Verschuere, B, 2019). When developing processes of co-production, tasks and/or objectives are established exante by a public administrator/official/agency. In this form, private partners are less involved, being constrained by predetermined tasks set up by public entities and the public servant is assumed to have more control. Conversely, co-creation happens when there are no objectives set in advance; rather objectives have to be established through negotiation and participation (Velotti, Botti and Vesci, 2012; Dudau, Glennor and Vershirer, 2019). Understanding co-production and co-creation as the result of negotiation and participation does not highlight the fact that these partnerships are often aimed at the production of a service or part of a service and that the coproduction of services is "an essential and inalienable core component of service delivery". According to this perspective co-production entails the conscious or unconscious participation of the user in the delivery of the service as well as the creation or destruction of value (Osborne, Radnor and Strokosch, 2016).

The literature on public administration primarily discusses the co-production and co-creation of value for public goods or services. The term value often refers to public value (Moore, 1995) and this can be an output, a product, and/or an outcome of public services or policies. However, value 
can also be understood at the individual level as motivation of individuals to co-create or coproduce services (Pestoff, 2012). More recently Lindgren et al (2019) have demonstrated how public value can be produced and/or created at the level of the individual as well as at the collective level and that it can be produced or created at the same time as private value is being created.

Thus, public and private entities and citizens can create public and private value and may at times create both simultaneously.

In addition to the literature on public services there are several studies that address the coproduction and co-creation of knowledge in other related disciplines. One example of the coproduction of knowledge and policies is in science-policy co-production (Miller, 2001; Jasanoff, 2004; Scolobig et al., 2014;). Science-policy co-production results from the interaction of scientists, citizens/end users and policy makers (Scolobig, 2016). For instance, in Italy the coproduction of experiences of co-creation can be found in engaged academics and engaged scholarship and in innovative experiences of partnerships between academy and community partners. Engaged scholarship or the engaged academic is a scholar that is committed to high academic standards and "actively works to create useful knowledge and ... connects with real communities and organizations involved in disasters and emergency management (Trainor, Stern and Stubbio 2018, p. 166).

However, despite an increasing tendency, in some countries, to develop and implement policies that are co-produced and/or co-created by politicians, scientists and the public at large a problematic aspect that should be taken into account is the question of who determines what deserves to be co-produced or co-created and who are the entities included in this participatory process. The response of the United States to COVID 19 illustrates how competing values and therefore interests might interfere with response. For instance, the United States has initially downplayed the danger of COVID 19 in an attempt to protect

(...) economic activity over the recommendations of public health officials and medical experts. This appearance of distrust in science, and in scientists, only exacerbates an erosion of public trust. It also calls into question the extent to which decisions in response to the crisis are made on the basis of data and evidence. All of these factors highlight an urgent need for scientists, public health experts, engineers, federal and local agencies and those in the private sector to step up and act on behalf of the greater societal good (New Voices in Sciences, Engineering \& Medicine initial cohort, March 18, 2020).

Thus, the question that arises is what is the greater societal good? Is the greater societal good responding to a health crisis or to protecting economic activity?

\section{Papers in this issue}

The papers in this special issue are primarily empirical and address co-production and co-creation from the perspective of the individual (Baker and Deham; Malinen, Algera and Mankkinen, and Bakker and colleagues), and the organizations operating within networks of emergency 
management systems (Sienkiewicz-Małyjurek, Caliskan and Altintas and Murphy, Wankhade and Lakoma). The methods used by the authors are both quantitative and qualitative.

Baker and Deham have used an innovative way for researchers to co-create knowledge. Going beyond participant observations, they propose and exemplify the perspective of the researchers as a citizen responder as a means to gain in-depth knowledge about processes and service delivery. In this instance co-creation of knowledge and value is, at least partly based on reflexivity.

They discuss how a "regime" narrative about the use of governmental agencies as first responders is produced and reproduced in the emergency management sector and the implications this has on informal response from participants such as citizen volunteers. A "regime" narrative is a unilateral version of the facts, in this case the version of the formal or official response establishment. The article discusses the conflict generated by the creation of value for survivors and citizen volunteers during informal response operations and the destruction of value for official responders. It also raises questions on the co-production of "regime" or dominant perspectives. It juxtaposes an alternative perspective, namely the creation of an innovative co-created narrative of aid in post disaster relief, where survivors are seen as an integral part of the response systems. The study focuses on the response of spontaneous volunteers in search and rescue operation during Hurricane Harvey in the Houston area in 2017. The Houston area was subjected to unprecedented rain that caused many areas to flood. Since the turn in weather was sudden, the population was not asked to leave but to stay in their homes. Baker and Deham base their discussion on the observation of three epiphanies, the epiphany of unstrapping, the epiphany of de-securitization and the epiphany of appropriation. In the authors view the response of spontaneous volunteers is an example of less formalized public private partnerships, co-production and co-creation. Their article is also the first time that the authors methodology of co-autoethnography have appeared in this journal.

Volunteering is also the subject of the paper by Malinen, Algera and Mankkinen. In terms of our theme, the motivation to continue volunteering for the fire service can be understood as service co-production since volunteers are asked to perform specific tasks on the basis of established procedures. While large urban areas generally benefit from full-time career firefighters, sparsely populated areas often rely more on volunteers. Long-term volunteer numbers have recently been declining in many countries. The authors have used a large on-line survey and the well-established Volunteer Functions Index to investigate the initial motivations of volunteers to join the Finish fire service and the (much less researched) motivations of those who come back and continue volunteering for the service. The authors then look at the role of socio demographic variables such as gender and age and at regional differences (using urban, semi-rural and rural areas) to explore variations in the motivation to volunteer. This fascinating study finds significant differences in almost all of these factors and distinct differences to findings in the general volunteer literature. There are differences in the motivation to join the service from those continuing to stay with the service and variations in both when gender, age and geography are factored in. The only common factor was that there were no significant regional differences in the initial decisions to volunteer. Overall, the initial motivation to volunteer is due to volunteers' willingness to gain skills or an understanding of the fire brigade, secondly the influence of their relatives to join and then as a third factor there are values such as wanting to do good. Although the authors acknowledge the inherent limitations of a study based in one country, the theoretical and practical implications are considerable and the need to replicate the study and validate the findings is demonstrable. The study also confirms that motivations are dynamic and can change over time and the paper sheds light on the transactional aspect of service co-production in the fire and rescue service. 
Bakker, van Veldhoven, Gaillard, Hertogs and Feenstra present an exciting new questionnaire for the assessment and early diagnosis of potential problems in the functioning of emergency workers in their private life outside work. Rescue workers particularly those in the front line have demanding jobs and previous research has shown that an accumulation of involvement in critical incidents makes the rescue worker susceptible to the development of psychological symptoms. Most studies to-date emphasize the risks of rescue workers' sacrificing their health and private life. Building on earlier work that identified the most important life tasks as being, social life; maintaining family, home and finances; maintaining mental health, providing meaning and maintaining positivity the study developed a Life Tasks Test to help the diagnosis of rescue workers and protect them against the corrosive effect of "cumulative confrontation with adversities". It was the first questionnaire to be designed and implemented specifically for emergency workers and was based on the response from 108 police officers in urban areas in the Netherlands. The team's results found the test valid for four of the five life task domains although they found little evidence for the validity of the social life domain with the exception of 'support from colleagues' which is related to the quality of the social network at work. With such a small study in one service, and one country there are obvious and acknowledged issues with generalizability but the potential practical implications for management, workers and their trainers being able to co-create individual and collective value are clear and substantial.

The article from Caliskan and Altintas on patient transfers by air ambulances and seaborne transport (in this instance an ambulance boat or a ferry) in addition to or in combination with traditional road vehicles, is a contribution to the very limited information and literature that we have on the performance of these types of specialist services. Performance appraisals of ambulance services tend to focus on two sets of performance criteria. The clinical contribution of the service to the patient and the response time or duration in getting patients from the call out to their arrival at hospital (with cost being a factor in both). Although there are medical journals that accept papers on the clinical performance and patient outcomes of those transferred by these specialist services, the current paper is purely about non-clinical performance. Exiting studies also tend to be in the more affluent countries and are often focused or based on large urban areas. The current paper is part of an attempt by the authors and colleagues to build upon a series of studies that look at the performance of these specialist services in Turkey. Turkey is obviously a large country with significant numbers of islands and archipelagos. In particular, this is a study of the helicopter and seaborne services to two islands in the Aegean Sea where multiple transfers from different types of ambulance can result in varying response times. As well as being in a 'literature poor' research environment the authors are also dealing with a 'data poor' environment and have had to use patient registration forms for the 5-year period up to 2013. The study found both seasonal and weekly variations in transfers are affected by factors as diverse as operating times and the weather. All types of transfers where higher in the summer due to tourism. Although the current paper is largely descriptive, we hope it will encourage the study of similar specialist services in the future perhaps through comparative studies.

Katarzyna Sienkiewicz-Małyjurek discusses the background and antecedents of collaboration and the drivers of relational risk in public safety networks (PSNs) based on the current emergency management arrangements in Poland. In Poland, public safety is the responsibility of state authorities at both the central and local government level. The aim of the article is to "identify the 
inter-related impact of the antecedents of collaboration on the emergence of relational risk and the impact of relational risk on the effectiveness of collaboration in public safety networks". The study answers two research questions aimed at understanding which of the antecedents of collaboration influences the emergence and extent of relational risk in PSNs and how drivers of relational risk impact upon collaborative effectiveness in PSNs. The antecedents or drivers of collaboration identified by the author are legal requirements, organizational dependency, institutional complementarity, past experience and common problems. Relational risk refers to the risk an organization takes when engaged in collaborative relationships. The outcomes from collaborative relationships can be influence by a lack of reciprocity, enmity and/or different cognition (misunderstanding the necessity of collaboration, lack of dependency awareness). The study's findings are based on a sample of 83 of 100 correctly completed questionnaire of professionals and practitioners from emergency and rescue units, including the police, state fire brigade and emergency medical services; local government officials responsible for security issues; and academics research workers working in PSNs. Utilizing a structural modeling equations method, the author finds that legal requirements and past experience most affect the emergence of relational risk, while different cognition and enmity have the greatest impact on the effectiveness of collaboration. Though the author accepts that these findings need to replicated in other contexts; they can be considered as the first steps toward a better understanding of factors influencing collaboration and therefore the co-production of service and the creation of value in similar PSNs and possibly for any organizations working in network settings or in partnerships.

The article by Murphy, Wankhade and Lakoma is a general review paper that offers a way to examine the performance regime of emergency services by identifying the roles and responsibilities that are involved in the inter-related domains of policy development, public service delivery and public assurance. The article shows how these activities are related to each other and to wider considerations such as underpinning public service values, the operating environment and the resources available to the service at any one time. In the past, the model has been applied to a range of locally delivered public services including local government, health and social care and the police. As its title suggests, this article focusses on the strategic and operational landscape of the three 'blue light' emergency services in the UK (the police, fire and ambulance services), as the organizational landscape has recently been changing rapidly and there are further foreseeable changes in the future. Their purpose is to 'map the overall picture', so that future research can look at the strengths and weaknesses, and perhaps identify potential improvements in the organizational landscape or the conceptual framework, although the authors admit that they may have "strayed into subjective or evaluative areas when comparing the current landscape to ones that have existed in the past". Indirectly the paper identifies challenges to systemic innovation, improvement coproduction and co-creation in emergency services in the United Kingdom. It might also be useful as a contribution or starting point for investigating strengths and weaknesses in the organizational landscape and performance management regimes of public services in other countries.

\section{Conclusions and further research}

The special issue provides an interdisciplinary platform and a forum for an engaged and critical analysis of the emergency services amidst mounting calls for professionalization in these 
organizations along with the growing interest and capacity of the professionals and practitioners (in these services) for co-production and co-creation of knowledge. Collectively the papers have highlighted how the creation of value is not a given, since it can vary depending on the perspective assumed. Baker and Deham for example highlight how the creation of value for citizens and volunteers as first responders might represent a destruction of value for professional responders. This presents a challenge for both scholars and practitioners of how to create a system in which all the parts work together towards achieving a common goal and how to make sure that all the entities involved feel part of the same venture and aspirations. Is it unreasonable to suggest that, in essence, this is the challenge posed by the Covid-19 virus pandemic? Does it require an existential threat to generate the focus for this collective endeavor? and if so, why hasn't it yet happened with climate change?

Individually all of the papers either directly or indirectly ask serious questions of current arrangements for the provision and deployment of emergency services. From the inadequacy of basic data in specialist ambulance services (Caliskan and Altintas) to the needs of our human resources (Mallinen et al, Bakker et al ) or the inter-related systems we adopt for preparedness, response and recovery (Baker and Deham, Sienkiewicz-Małyjurek and Murphy et al ), you only have to ponder the current Covid-19 pandemic to see how relevant these issues are. The case for collaboration co-production and co-creation in the emergency services is ever more compelling. The need for further research undeniable.

\section{Acknowledgements}

The editors of this special issue thank all the authors that have contributed with their articles to further the debate on co-production and co-creation of value in emergency services and emergency management. A special thanks goes to Dr. Paresh Wankade, the chair of the panel on service coproduction and co-creation in emergency services.

\section{References}

Boivard, T. (2007). Beyond Engagement and Participation: User and Community Coproduction of Public Services. Public Administration Review, 67 (5): 846-860

Chatfield, A. T., Scholl, H. J., and Brajawidagda, U. (2014, January). \# Sandy tweets: citizens' co-production of time-critical information during an unfolding catastrophe. In 2014 47th Hawaii International Conference on System Sciences (pp. 1947-1957). IEEE.

Dilling, L., and Lemos, M. C. (2011). Creating usable science: Opportunities and constraints for climate knowledge use and their implications for science policy. Global environmental change, 21(2), 680-689.

Dudau, A., Glennon, R. and Verschuere, B. (2019) Following the yellow brick road? (Dis)enchantment with co-design, co-production and value co-creation in public services. Public Management Review, 21(11), pp. 1577-1594.

Jasanoff, S. (2004) The idiom of co-production. In: Jasanoff S (ed) States of knowledge: the coproduction of science and social order. Routledge, London, pp 1-13 
Johnson, B (2020) PM statement on coronavirus: 16 March 2020. Prime Minister's Office London TSO.

Lindgreen, A, Koenig-Lewis, N., Kitchener, M., Brewer, J., Moore M., and Meynhardt, T. (2019). Public Value: Deepening, Enriching, and Broadening the Theory and Practice of Creating Public Value. Abingdon: Routledge.

Miller, C.A., 2001. Hybrid management: boundary organizations, science policy, and environmental governance in the climate regime. Sci. Technol. Human Values 26 (4), 478-50

New Voices in Sciences, Engineering \& Medicine initial cohort. (March 18, 2020). How the U.S. Must Respond to the COVID-19 Pandemic. Retrieved on March 27, 2020 from: https://blogs.scientificamerican.com/observations/how-the-us-must-respond-to-the-covid-19pandemic/

Osborne, S. P., Radnor, Z. and Strokosch, K. (2016). Co-Production and the Co-Creation of Value in Public Services: A suitable case for treatment? Public Management Review, 18(5), pp. 639-653.

Pestoff, V. (2012). Co-production and third sector social services in Europe-Some crucial conceptual issues. In V. Pestoff, T. Brandsen, \& B. Verschuere (Eds.), New public governance, the third sector and co-production (Chap. 2). London: Routledge.

Rafter, F. (2013). 20. Volunteers as Agents of Co-production:'Mud armies' in emergency services. Putting Citizens First, 187.

Ramsey, M. M., Muñoz-Erickson, T. A., Mélendez-Ackerman, E., Nytch, C. J., Branoff, B. L., \& Carrasquillo-Medrano, D. (2019). Overcoming barriers to knowledge integration for urban resilience: A knowledge systems analysis of two-flood prone communities in San Juan, Puerto Rico. Environmental Science \& Policy, 99, 48-57.

Scolobig, A., Mechler, R., Komendantova, N., Liu, W., Schröter, D., \& Patt, A. (2014). The coproduction of scientific advice and decision making under uncertainty: lessons from the 2009 L'Aquila earthquake, Italy. Planet@ risk, 2(2), 71-76.

Scolobig, A., \& Pelling, M. (2016). The co-production of risk from a natural hazards perspective: science and policy interaction for landslide risk management in Italy. Natural Hazards, 81(1), 725 .

Trainor, J., Stern, E., and Stubbio, T. (2018) On Research and Practice in Disaster Science and Management. In Handbook of Disaster Research. H, Rodríguez., W, Donner and J, E. Trainor (Second Edition). New York: Springer. 
Velotti, L., Botti, A., \& Vesci, M. (2012). Public-Private Partnerships and Network Governance: What Are the Challenges? Public Performance \& Management Review, 36(2), 340-365. 